\title{
O ensino de física para jovens com deficiência intelectual: uma proposta para facilitar a inclusão na Escola Regular
}

The teaching of physics for young people with intellectual disabilities: a proposal to facilitate inclusion in the Regular School

La enseñanza de física para jóvenes con discapacidad intelectual: una propuesta para facilitar la inclusión en la Escuela Regular

\section{* Ângela Maria dos Santos}

Professora doutora do Instituto Federal Paraná, Curitiba, Paraná, Brasil.

Angela.dossantos@ifpr.edu.br

\section{** Paulo Simeão Carvalho}

Professor doutor da Universidade do Porto, Porto, Portugal.

Psimeao@fc.up.pt

\section{*** Janeide Lima Alecrim}

Doutoranda da Universidade do Porto, Porto, Portugal.

Janeide_lima@ufam.edu.br

Recebido: 09 de julho de 2017

Aprovado: 18 de março de 2018

\section{RESUMO}

Este trabalho é uma pesquisa que possui o intuito de encontrar e divulgar métodos que facilitem o processo de aprendizagem no ensino de Física, para jovens e adolescente, com deficiência intelectual e/ou défice cognitivo. O projeto foi desenvolvido com estudantes do terceiro ciclo do ensino público de Portugal, com idades entre quinze e dezessete anos, atendidos pela educação especial da escola, mas que frequentam sala de aula regular. $\mathrm{O}$ objetivo geral foi perceber quais os métodos e ferramentas pedagógicas que promovem ou facilitam a aprendizagem científica, considerando, neste caso, o ensino de Física. Foram escolhidos três estudantes de séries diferentes, com deficiências cognitivas de níveis diferentes e foram feitos encontros semanais individuais e avaliou-se, através de elementos que foram definidos como evidências do aprendizado, o que os diferentes métodos poderiam auxiliar na compreensão dos conceitos que haviam sido trabalhados em sala. Utilizou-se métodos distintos de ensino com diferentes ferramentas pedagógicas, apoiadas no trabalho de Vygotsky e, através da Taxonomia de Bloom, definiu-se o nível de 
http://dx.doi.org/10.5902/1984686X27590

aprendizagem para cada tópico trabalhado. Foi possível confirmar que para que exista realmente uma escola inclusiva é necessário que os métodos tradicionais de ensino sejam mudados, que os trabalhos em grupo e as tecnologias educacionais sejam utilizadas em sala de aula e que também sejam considerados currículos adaptados para cada caso. Palavras-chave: Educação inclusiva; Ensino de física; Deficiência intelectual

\section{ABSTRACT}

This work is a research that aims to find and disseminate methods that facilitate the learning process in physics teaching, for young people and adolescents, with intellectual disability and/or cognitive deficit. The project was developed with students from the third cycle of public education in Portugal, aged between fifteen and seventeen, attended by the school's special education and also attending a regular classroom. The general goal was to understand the methods and pedagogical tools that promote or facilitate the scientific learning considering the teaching of Physics. Three students from different grades were chosen with intellectual disabilities of different levels and individual meetings were done and assessed how the different methodologies could help in the understanding of the concepts that had been worked in the room. We used different teaching methods with different pedagogical tools, based on Vygotsky's work and, through the Bloom Taxonomy, we defined the level of learning for each topic. It was confirmed that actually to promote an inclusive school it is necessary that the methods are changed, the group work and technologies are used in the classroom and are also considered tailored curricula for each case.

Keywords: Inclusive education; Teaching of physics; Intellectual disability.

\section{RESUMEN}

Este trabajo es una investigación que tiene el propósito de encontrar y divulgar métodos que faciliten el proceso de aprendizaje en la enseñanza de Física, para jóvenes y adolescentes, con discapacidad intelectual y / o déficit cognitivo. El proyecto fue desarrollado con los alumnos del tercer ciclo de la educación pública en Portugal, con edades comprendidas entre los quince y diecisiete años, servida por la escuela de educación especial, pero que asisten a clase regular. El objetivo general fue percibir cuáles son los métodos y herramientas pedagógicas que promueven o facilitan el aprendizaje científico, considerando, en este caso, la enseñanza de Física. Se eligieron tres estudiantes de diferentes series, con deficiencias cognitivas de diferentes niveles y se realizaron encuentros semanales individuales y se evaluó, a través de elementos que se definieron 
http://dx.doi.org/10.5902/1984686X27590

como evidencias del aprendizaje, lo que los diferentes métodos podrían auxiliar en la comprensión de los conceptos que habían sido trabajados en sala. Se utilizó métodos distintos de enseñanza con diferentes herramientas pedagógicas, apoyadas en el trabajo de Vygotsky y, a través de la Taxonomía de Bloom, se definió el nivel de aprendizaje para cada tópico trabajado. Es posible confirmar que para que exista realmente una escuela inclusiva es necesario que los métodos tradicionales de enseñanza sean cambiados, que los trabajos en grupo y las tecnologías educativas sean utilizadas en el aula y que también sean considerados currículos adaptados para cada caso.

Palabras clave: Educación inclusiva: Enseñanza de física; Deficiencia intelectual.

\section{Introdução}

A educação inclusiva apesar de constar em lei de países que assinaram a declaração de Salamanca em 1994 (UNESCO, 1994) ainda é uma situação que traz questões a serem enfrentadas e melhoradas nas salas de aula, seja na educação brasileira, seja na educação portuguesa.

Incluir significa não apenas colocar no mesmo espaço, mas permitir que todos utilizem a escola e se apropriem dos mesmos conhecimentos tendo ou não deficiência. É ainda comum, de forma geral, a sociedade tratar pessoas com deficiência a partir das dificuldades manifestadas e não considerando todas as potencialidades que estes indivíduos possuem.

Até meados da década de 1990 a deficiência intelectual era definida a partir de níveis de quociente de inteligência (Q.I.) que cada pessoa obtinha através de testes que eram realizados pela área da psicologia clínica ou médica. Atualmente, entretanto, a American Association on Intellectual and Developmental Disabilities $(A A I D D)$ caracterizou esta deficiência a partir de um sistema baseado em apoios necessários, enfatizados desde 1992, considerando que:

\footnotetext{
Deficiência intelectual é a incapacidade caracterizada por importantes limitações, tanto no funcionamento intelectual quanto no comportamento adaptativo e está expresso nas habilidades adaptativas conceituais, sociais e práticas. Tem início antes dos 18 anos. (LUCKASSON, 2002, p.8)
}

A partir desta definição é possível perceber que pessoas com deficiência intelectual possuem limitações, mas devem ser estimuladas para que haja 0 desenvolvimento cognitivo de estruturas superiores. É importante salientar que 
http://dx.doi.org/10.5902/1984686X27590

existem diferentes sistemas de classificações, mas o da AAIDD tem sido referência aos demais sistemas, considerando a classificação e o diagnóstico da deficiência intelectual.

Os apoios necessários, considerados nesta classificação, são definidos de acordo com suas intensidades. Quando se fala de escola, o espaço que é exclusivamente considerado neste trabalho, os apoios são extensivos, pois possuem regularidade (CARVALHO, 2003).

Estes sistemas de apoios estão relacionados com a zona de desenvolvimento proximal de Vygotsky que indica a existência de uma região de desenvolvimento cognitivo potencial, que é uma região média entre o que se resolve sozinho e o que é possível de ser resolvido com a intervenção de um adulto mediador (VYGOTSKY, 1978) , isto é, segundo o autor, o que se faz hoje com auxílio, é possível de ser atingido em outra época, sem ajuda. Dessa maneira, ensinar ciências, em específico física, para alunos adolescentes e jovens com deficiência cognitiva e também deficiência intelectual, e avaliar as necessidades do que pode ser feito com auxílio e o que não se consegue, mesmo que individualmente, é uma maneira de auxiliar professores de sala de aula regular a programarem e reprogramarem suas aulas e metodologias, para verdadeiramente incluírem os alunos com algum tipo de deficiência em sala de aula.

Para desenvolver o potencial cognitivo de adolescentes e jovens com deficiência intelectual ou apenas algum défice cognitivo é imprescindível que se conheça estes alunos, que se tenha um acompanhamento das potencialidades e dificuldades encontradas, que se avalie não apenas o espaço escolar, mas também que a escola reconheça a família e a sociedade em que este indivíduo está inserido.

No processo de ensino e aprendizagem, principalmente de estudantes com deficiência intelectual, faz-se necessária a mediação. Mediar é um processo educacional que leva em consideração o conhecimento, o desenvolvimento, o respeito e a percepção de que todo indivíduo está apto para aprender. A mediação deve ter uma intencionalidade e deve sempre desenvolver a habilidade do processo de aprender (FEUERSTEIN, 1980). Neste contexto, mediar significa sistematizar aspectos do ensino e do conteúdo que podem provocar uma modificabilidade no cotidiano deste aluno. 
http://dx.doi.org/10.5902/1984686X27590

Para que realmente aconteça o processo de aprendizagem, é imprescindível que qualquer sujeito assimile o que é apresentado e acomode esta nova informação através de diversas apresentações do novo aprendizado, de desconstrução e organização para uma evolução e amadurecimento para relações simples e complexas (GONÇALVES, 2012). No entanto, aprender não pode ser apenas assimilar o que é ensinado; aprender deve fazer sentido, deve provocar uma mudança de atitude perante o meio.

Adolescentes e jovens com deficiência intelectual ou com algum défice cognitivo devem ter suas habilidades intelectuais desenvolvidas de formas alternativas (MANTOAN, 1999). Isto quer dizer que o processo de ensino e aprendizagem deve ser feito de maneira a aprimorar e perceber a capacidade intelectual de cada aluno. Considerando esta questão, escolas e salas de aula tradicionais não auxiliam o desenvolvimento cognitivo de muitos estudantes, visto que os conteúdos são lançados, com muita frequência, para o cumprimento de cronogramas e não para um enriquecimento social e cultural.

Focando o ensino das Ciências, em particular, no ensino de Física, é imprescindível que esta disciplina seja não apenas um acumulado de informações e números, mas que seja efetivamente parte do cotidiano dos estudantes, e represente algum tipo de significado para os que tenham ou não alguma deficiência. Assim, muito além do conteúdo, é fundamental fazer esta ciência ser percebida pelo estudante, é importante que ela parta de um aspecto motivacional e que realmente agregue informações e significados que venham a provocar modificabilidade na sua visão de mundo.

O ensino de Física ainda enfrenta, em sua maioria, aspectos muito tradicionais, conteudistas e matemáticos de forma geral. Partindo da necessidade de uma escola inclusiva, onde todos os alunos devem aprender no mesmo espaço e sem distinções, é fundamental que a escola se modifique, e que cada aluno possa se apropriar de seu aprendizado para que seu desenvolvimento intelectual e social seja efetivo.

Para que estas mudanças possam acontecer é importante que novas pesquisas ocorram através de abordagens diretas com estudantes, fazendo uma avaliação de métodos que possam auxiliar o aprendizado de Física, por alunos jovens, 
http://dx.doi.org/10.5902/1984686X27590

com deficiências cognitivas, considerando o processo de mediação, de repetição, de familiarização e também de motivação destes estudantes. É exatamente este tipo de pesquisa que é relatado neste trabalho.

O processo de aprendizagem dos estudantes é avaliado através de um instrumento que apoia o planejamento pedagógico conhecido como taxonomia de Bloom (BLOOM, 1971). Esta taxonomia busca ordenar os níveis cognitivos e permite que os objetivos educacionais possam ser medidos, ordenando materiais de avaliação e domínios cognitivos (MONTEIRO, 2012). Esta taxonomia foi revisada em 2001 por um outro grupo de especialistas juntamente com um dos membros do primeiro estudo.

A revisão da taxonomia de Bloom foi projetada para auxiliar professores a compreender e melhorar currículos baseados em padrões e para isto, separou o conhecimento em dois grupos: conhecimento como processo e conhecimento como conteúdo assimilado (ANDERSON, 2001), em cada um dos grupo são utilizadas caracterizações com relação ao nível de aprendizado.

Dentro desta revisão, neste trabalho, o processo de aprendizagem foi categorizado como: conhecimento efetivo - quando há apenas reprodução; conhecimento conceitual - quando há categorização; conhecimento procedural quando existe a utilização de diferentes técnicas e generalizações e conhecimento metacognitivo - quando existe profundidade e estratégias no conhecimento. $O$ conhecimento metacognitivo não foi levado em consideração, neste trabalho, devido ao aspecto extremamente abstrato do ensino de Física para alunos com deficiência intelectual acentuada, ou seja, aqueles alunos que anteriormente eram avaliados com quociente de inteligência (Q.I) abaixo de cinquenta por cento e que hoje, comparados com colegas da mesma faixa etária, possuem dificuldades de comportamento e de aprendizagem em quaisquer áreas de conhecimento.

\section{Justificativa e desenvolvimento da pesquisa}

O ensino de Física tem ainda hoje insuficientes pesquisas na área de educação de pessoas com deficiências. Isso acontece tanto no Brasil quanto em Portugal. Existe, atualmente, um considerável aumento nos estudos para o ensino de pessoas com deficiência auditiva e deficiência visual (CAMARGO, 2006), mas na área de 
http://dx.doi.org/10.5902/1984686X27590

transtornos globais do desenvolvimento e de deficiência intelectual ainda nada se encontra na literatura.

A pesquisa desenvolvida neste trabalho faz uma abordagem no processo de ensino e aprendizagem em Física, com estudantes jovens do terceiro ciclo de uma escola regular, em Portugal, que também possuem acompanhamento da educação especial. Os jovens que participaram deste estudo possuem currículos adaptados, isto é, não frequentam todas as disciplinas que os colegas matriculados na mesma série e também fazem trabalhos de séries do primeiro ou segundo ciclos. No conteúdo de Física, estes estudantes participam da série em que estão matriculados sem, entretanto, possuírem atividades adaptadas.

O trabalho desenvolvido buscou avaliar os diferentes métodos e procedimentos didáticos no processo de aprendizagem de cada aluno, considerando seus gostos, suas idades e os conteúdos vistos em sala de aula regular. Os dados coletados relacionam o conhecimento prévio destes estudantes, apenas com as aulas de sala de aula regular, antes do processo de mediação mais individualizado e o conhecimento após o processo de mediação, considerando os métodos abordados em cada etapa do processo de ensino e aprendizagem de Física.

Além do processo qualitativo abordado na pesquisa, usa-se também um aspecto quantitativo no que diz respeito à quantidade de assuntos abordados com os diferentes estudantes, à análise do que foi efetivamente aprendido e às estratégias usadas. Avalia-se, assim, como as abordagens realmente produziram uma modificabilidade e que aspectos não auxiliaram no processo de aprendizagem em cada caso, considerando cada assunto abordado.

Para concretizar a mudança de métodos de ensino, é imprescindível que novas pesquisas sejam realizadas de maneira a perceber como estudantes com deficiência intelectual ou algum défice cognitivo interiorizam a ciência exata, qual a aplicabilidade dela em seu ambiente e como a acomodação do conteúdo pode ser feita, individualmente e em sequência, no trabalho em grupo.

Para além da educação básica, este estudo também buscou encontrar respostas para a educação profissional e tecnológica de estudantes com deficiências intelectuais e cognitivas, considerando o ensino de Física que é uma disciplina que exige um certo 
http://dx.doi.org/10.5902/1984686X27590

grau de desenvolvimento abstrato. Antigamente, estes estudantes frequentavam cursos técnicos nas áreas em níveis menos complexos no aspecto cognitivo mas hoje, no Brasil, estão dentro de centros técnicos e tecnológicos e têm direito de possuir o mesmo diploma que os demais estudantes, pelo que devem atingir níveis equivalentes de aprendizagem. Assim, dentro das diferenças, é imprescindível que alunos com ou sem deficiência estejam em sala de aula e que o processo de ensino e aprendizagem forme indivíduos mais autônomos e mais socialmente adaptados, inclusive no que diz respeito ao aprendizado da ciência Física.

\section{Abordagens e discussões}

\section{A escola portuguesa}

A educação básica portuguesa é dividida em quatro ciclos: o primeiro ciclo corresponde ao que seriam os três primeiros anos do ensino fundamental no Brasil, o segundo ciclo corresponde aos três anos seguintes, o terceiro ciclo aos três últimos anos do ensino fundamental e o secundário corresponde ao ensino médio no Brasil. As escolas portuguesas possuem profissionais responsáveis pelo atendimento e acompanhamento dos alunos com necessidades específicas, isto é, cada estudante ou grupo de estudantes tem um profissional responsável pelo apoio e pelo auxílio ao professor de sala de aula regular.

É o professor da educação especial quem faz o acompanhamento e define o currículo adaptado de cada estudante. É possível encontrar, em salas de aula regulares, alunos que estão cursando, em algumas disciplinas, a matéria corrente do ano em que estão matriculados, enquanto em outras disciplinas cursam conteúdos de anos anteriores. Isso é muito comum, inclusive, com alunos com deficiência intelectual, que podem não cursar disciplinas nas áreas de exatas ou cursar as disciplinas do primeiro ou segundo ciclos. É comum também encontrar estudantes que apenas estão incluídos em disciplinas desportivas e artísticas e nos demais momentos, permanecem nas salas de apoio com educadores especiais.

Existem espaços onde os estudantes são atendidos e há, também, diversos profissionais para o acompanhamento dos estudantes com deficiência, não apenas um profissional para toda a escola. A escola em que a pesquisa foi desenvolvida contava com oito professores da educação especial na especialização multideficiência 
http://dx.doi.org/10.5902/1984686X27590

para 0 atendimento de quarenta e seis alunos. A formação para o trabalho com estudantes da educação especial, em Portugal, é dividida em três categorizações: a especialização para o trabalho com alunos surdos, a especialização para o trabalho com alunos cegos e a especialização para alunos com défice cognitivo e deficiências múltiplas. Normalmente estes profissionais são formados nas escolas superiores de educação, que corresponde aos cursos de pedagogia no Brasil.

Apesar deste aspecto, ainda existem problemas na relação escola especial - sala de aula regular. Infelizmente, como no Brasil, falta o conhecimento das áreas específicas para os profissionais da educação especial e falta o conhecimento da educação especial para os professores de sala de aula regulares, que muitas vezes não se apercebem da necessidade de mudanças atitudinais para um verdadeiro processo de inclusão dos alunos com necessidades específicas. Falta também um processo de inclusão mais integrado, isto é, os alunos atendidos pela educação especial, em muitos momentos, não participam dos intervalos com os demais estudantes, pois permanecem na sala de atendimento para fazer os lanches, enquanto os demais alunos estão no pátio da escola.

A educação obrigatória até aos dezoito anos ou até ao final do secundário é recente em Portugal (PORTUGAL, 2009). Até 2009 a educação era obrigatória até aos quinze anos ou ao fim do terceiro ciclo escolar, correspondente ao nono ano no Brasil. Depois deste período os alunos com deficiência ou paravam seus estudos, ou entravam em escolas especiais que ainda existem no país. Devido ao pouco tempo da nova legislação, ainda se encontram poucas escolas de secundário com alunos cujas deficiências intelectual e cognitiva sejam mais profundas, por isso o trabalho aqui apresentado analisou perfis de estudantes com mais de treze anos de idade, mas ainda em terceiro ciclo escolar.

\section{Perfil dos estudantes}

O trabalho desenvolvido ocorreu em uma escola regular, do norte de Portugal, com três estudantes do terceiro ciclo, com idades entre quinze e dezessete anos de idade.

O aluno A1 tinha dezesseis anos, estava matriculado no nono ano, terceiro ciclo, tinha uma avaliação de microcefalia progressiva e atraso global de desenvolvimento 
http://dx.doi.org/10.5902/1984686X27590

psicomotor. Segundo seu perfil de funcionalidade possuía dificuldades de atenção, psicomotoras, cognitivas básicas, intelectuais e de cálculo. Este aluno assistia as aulas de físico-química juntamente com os colegas na classe regular, mas não fazia qualquer avaliação conjuntamente com eles. As aulas de física nesta classe eram tradicionais, o professor era o centro do conhecimento e os alunos permaneciam sentados, em fileira, observando e escutando as informações que o professor dava e passando para o caderno o que ele escrevia no quadro negro. Nestas aulas e, de acordo com o seu Perfil de Funcionalidade Individual (PEI) - que era um documento mantido na sala de atendimento especial e monitorado trimestralmente em reunião com todos os professores do estudante -, e em todas as demais aulas, o aluno A1, ficava muitas vezes disperso, não prestava atenção e apenas copiava algumas informações que o professor passava no quadro. Nas aulas da disciplina de matemática, este aluno possuía um currículo adaptado para o terceiro ano do primeiro ciclo. Não participava de todas as aulas com a mesma turma, mas ficava alguns tempos no apoio à educação especial.

O aluno A2 tinha quinze anos, estava matriculado no sétimo ano, terceiro ciclo, e segundo suas avaliações possuía limitações acentuadas nas funções mentais globais (relação espaço/tempo, domínios intelectuais, psicossociais, interpessoais e de temperamento), nas funções mentais específicas (atenção, memória de curto e longo prazo, função psicomotora e percepção visual e auditiva) e défices acentuados nas funções cognitivas de nível superior. Este estudante possuía pouco tempo de atendimento na educação especial, pois participava de todas as aulas juntamente com seus colegas de classe e possuía uma capacidade de autonomia mais acentuada que o estudante A1. Seu currículo era extremamente adaptado e ele ainda não havia desenvolvido competências mínimas relativamente ao ano em que estava matriculado. Era indicado, para este aluno, que estivesse matriculado em turma com quantidade de alunos reduzida.

O aluno A3 tinha quinze anos, estava matriculado no sétimo ano, terceiro ciclo, possuía uma avaliação de trissomia do cromossomo 21 e um atraso global do desenvolvimento. Segundo suas avaliações possuía alto nível de comprometimento nas funções mentais específicas (atenção e memória), limitações acentuadas nas funções mentais globais (domínios intelectual e de responsabilidade) e limitações 
http://dx.doi.org/10.5902/1984686X27590

acentuadas nas funções cognitivas superiores (abstração e dificuldade em gerir tempo). Este estudante, apesar de estar matriculado no sétimo ano, não participava de quase nenhuma aula da classe regular, fazia apenas aulas de educação física, teatro e história devido a sua dificuldade de interesse por quaisquer conteúdos acadêmicos.

Todos os três estudantes foram escolhidos, para a pesquisa, pelas professoras da educação especial, seja pelas suas avaliações individuais, seja pelas suas idades. O acompanhamento era feito todas as semanas, individualmente e durou o intervalo de tempo de oito meses. $\mathrm{O}$ aluno $\mathrm{A} 1$ tinha três tempos de quarenta e cinco minutos cada de aula de físico-química, sendo que um destes tempos foi utilizado para o projeto. Para o aluno A2 o projeto foi feito no seu tempo de apoio a educação especial, também um tempo de quarenta e cinco minutos. $O$ aluno $A 3$ também teve um dos seus tempos de apoio na educação especial, utilizado para o desenvolvimento do projeto

\section{Conteúdos de Física e métodos aplicados}

Sabe-se que a educação inclusiva requer uma verdadeira integração dos alunos em sala de aula. No entanto, neste projeto, os encontros foram feitos todos individualmente para buscar métodos que possibilitassem uma verdadeira inclusão dos alunos com deficiência intelectual em sala de aula regular, em disciplinas que requerem um desenvolvimento cognitivo abstrato mais acentuado.

Os dois alunos que frequentavam as aulas de físico-química nas classes regulares, tiveram o trabalho individual com os mesmos conteúdos vistos em sala de aula regular. O aluno que não frequentava a sala de aula regular na disciplina de físicoquímica, começou com o mesmo conteúdo que seus colegas de nível de ensino estavam aprendendo e depois, devido à dificuldade de atenção, foi-se mudando para conteúdos que parecessem de maior interesse para seu aprendizado.

Sabe-se que trabalhar conteúdos específicos, em uma abordagem conteudista não é interessante do ponto de vista do aprendizado. No entanto, seguindo a abordagem portuguesa, em que os alunos precisam fazer um teste nacional após o término do nono ano, optou-se por uma abordagem de conteúdo a partir de assuntos 
http://dx.doi.org/10.5902/1984686X27590

que pudessem trazer algum benefício aos estudantes que participavam do trabalho proposto.

Para começar a pesquisa primeiro foi feito um pequeno teste para perceber o que os estudantes sabiam sobre cada assunto, apenas através do dia a dia e do que haviam visto em sala de aula. Após estes testes as intervenções aconteciam, uma vez na semana, durante quarenta e cinco minutos, através de exposições diferentes, individualmente. Estas exposições foram avaliadas como auxiliares no processo de aprendizagem e a cada intervenção feita, avaliava-se se o aluno havia conseguido perceber mais o conteúdo com uma determinada ferramenta. Assim, avaliando o conjunto de métodos utilizados, obtinha-se um perfil de aprendizagem e caso ela tivesse acontecido de forma relevante, avaliava-se de que maneira havia ocorrido, para cada aluno.

A determinação da aprendizagem foi feita com base na taxonomia de Bloom revisada (ANDERSON, 2001), considerando os aspectos avaliados a cada encontro posterior aos assuntos trabalhados, ou seja, fazia-se a discussão de um assunto, com uma ferramenta ou mais, e no encontro seguinte fazia-se a avaliação do tema discutido. Assim, definiu-se nível de aprendizagem de 0 (zero) a 1 (um), sendo de 0 a 0,2 conhecimento efetivo, de 0,3 a 0,5 conhecimento conceitual, de 0,6 a 0,8 conhecimento procedural e de 0,9 a 1 conhecimento metacognitivo. Considerando-se o perfil dos alunos, a profundidade e as estratégias, representadas pelos conhecimento metacognitivo, não foram utilizadas.

Com relação aos demais tópicos, para a definição de 0,3 ou 0,5 , por exemplo, no conhecimento conceitual ou 0,6 ou 0,8 no conhecimento procedural, levou-se em conta os critérios apresentados na Tabela 1.

Para cada assunto trabalhado usou-se materiais distintos e métodos distintos de ensino e aprendizagem, como apresentado na Tabela 2. O método do aluno ouvinte está relacionado a aulas expositivas e tradicionais, onde o aluno apenas ouve, questiona e faz alguma atividade. O método do aluno pesquisador está relacionado ao aspecto de encontrar respostas através de questionamentos e postura independente para encontrar formas de explicar os fatos, já o método do aluno descobridor está relacionado ao fato de o aluno fazer parte das atividades, de ser o 
http://dx.doi.org/10.5902/1984686X27590

atuante em qualquer tarefa, ele precisa manipular e perceber o que é cada conceito, fazendo parte do aprendizado. O aluno descobridor e o aluno pesquisador, neste trabalho, são distintos porque considera-se que 0 aluno pesquisador tenha necessidade de maior estratégias para buscar respostas aos problemas, enquanto 0 aluno descobridor precisa de auxílio para as estratégias.

Para cada método empregado utilizou-se duas ou mais ferramentas, de maneira que fosse possível averiguar se houve ou não aprendizagem. A aprendizagem era definida através de objetivos que eram atingidos, parcialmente atingidos ou não atingidos e as maneiras de avaliação eram distintas, desde testes escritos, avaliação oral, desenhos ou conversas informais onde as questões eram arguidas.

Tabela 1- Critérios da escala de aprendizagem

\begin{tabular}{|l|l|l|}
\hline Conhecimento efetivo(reprodução) & Conhecimento conceitual(categorização) & Conhecimento procedural (técnicas) \\
\hline 0 - Não reproduz & 0,3 - Lembra do conceito & 0,6 - Explica com mesmos critérios \\
\hline 0,1 - Lembra do que foi feito & 0,4 - Entende o conceito & 0,7 - Utiliza outras técnicas para explicar \\
\hline 0,2 - Aplica a reprodução & 0,5 - Analisa o conceito & 0,8 - Sintetiza ou generaliza para explicar \\
\hline
\end{tabular}

Os três alunos que participaram da pesquisa possuíam defasagem nos conceitos de cálculo e abstração. Assim, as atividades foram pensadas de maneira a trabalhar conceitos e não aspectos matemáticos. Os objetivos eram previamente bem definidos e se o aluno conseguisse explicar de alguma maneira o que tinha sido trabalhado, determinava-se o grau da aprendizagem.

É importante salientar que a aprendizagem também foi avaliada pelo desenvolver dos alunos, lembrando que são estudantes com deficiência intelectual e cognitiva. Neste aspecto, confirma-se a importância de ter objetivos claros quando do processo de ensino e aprendizagem destes alunos no contexto da educação inclusiva. Estes alunos, em sala de aula regular, participarão das mesmas aulas e ser-lhe-ão ensinados os mesmo conteúdos, mas deverão ser avaliados de maneira diferenciada, considerando seus tempos e suas habilidades. Portanto, para haver uma educação inclusiva, a avaliação não pode ser igual, ela precisa ser adaptada tanto para alunos com deficiência como para alunos sem deficiência.

Muitas vezes foi preciso fazer a escolha de distintos métodos e distintas ferramentas, até encontrar algum princípio de aprendizagem. Esta maneira de 
http://dx.doi.org/10.5902/1984686X27590

trabalho, compreende-se, não é adequada em uma sala de aula regular, onde professores e demais alunos seguem um tempo pré determinado para o processo de ensino e aprendizagem. No entanto, considerando que um aluno com deficiência vai estar em sala de aula diariamente, e sendo o professor um mediador do conhecimento, é possível que ele perceba o que mais o auxilia no processo de aprendizagem. Esta pesquisa, acredita-se, pode ser uma base para este auxílio.

Tabela 2- Abordagens e temas trabalhados com cada aluno

\begin{tabular}{|c|c|c|c|c|}
\hline FERRAMEITAS & METOOOS & \multicolumn{3}{|c|}{ COIITEUDOS } \\
\hline Simulopobes & \multirow[b]{2}{*}{ Aluno ownte } & AlunoA1 & Aluno A2 & Aluno A3 \\
\hline Videos & & Vovimento Retilineo eAceerado (1) & Sistema Solar(1) & Sstema Soler (1) \\
\hline \multirow[b]{2}{*}{ Jogos dódátioos } & \multirow[b]{2}{*}{ Aluno pes ausador } & Pimeira Lei de New ton (2) & Planetas (2) & pes e Notes (2) \\
\hline & & Fercera lei de Newton (3) & Wovimentos de Tanslacio e Rotaço (3) & Fases da Lua (3) \\
\hline \multirow{3}{*}{$\begin{array}{c}\text { Repesentropoes conoretas de modelos físioss } \\
\text { Experimentos }\end{array}$} & \multirow[b]{3}{*}{ Aluno descobridor } & Prassio (4) & Fases da Lua (4) & Peneras (4) \\
\hline & & Velocidade e Acelesç bo (3) & Eolpse (3) & Rejernoial (5) \\
\hline & & Eletnioidade ( $(8)$ & Enegig (8) & pro e imagens (8) \\
\hline
\end{tabular}

As abordagens que foram realizadas através do método do aluno ouvinte, seja com vídeos, imagens ou simulações, poucas vezes surtiram efeito de aprendizagem plena, estes recursos ou eram encarados pelos alunos como meras fontes de informação, ou exigiam um grau de compreensão cognitivo que não estava ao seu alcance. Os alunos com deficiência intelectual, após algumas intervenções com este método, não conseguiam prestar atenção e repetidamente queriam fazer outra atividade.

Para estes alunos, as representações concretas de modelos físicos e os experimentos foram as ferramentas, que juntamente com o método do aluno descobridor, auxiliaram mais no processo de aprendizagem. $O$ método do aluno pesquisador, neste caso, talvez devido à falta de alguma autonomia, teve raros momentos de aprendizagem plena. É ainda importante ressaltar que após algumas tentativas sem efeito, este método não foi utilizado ao longo das demais intervenções.

Os jogos didáticos foram intercalados com algumas intervenções no sentido de desenvolver o aspecto cognitivo dos alunos, não sendo, necessariamente, jogos de aprendizagem. Eles também davam um tempo de descanso para os alunos, visto que devido ao aspecto abstrato de muitos conteúdos científicos, esses alunos cansavam com facilidade devido à necessidade de manter níveis de concentração elevados. 
http://dx.doi.org/10.5902/1984686X27590

Para as intervenções realizadas, os gráficos 1 e 2 mostram o comportamento da aprendizagem dos três alunos. As ferramentas utilizadas no método do aluno ouvinte eram imagens, vídeos ou simulações em que ele podia modificar os parâmetros, mas não podia modificar o aspecto das intervenções. Já no método do aluno descobridor, os experimentos e representações concretas podiam ser alterados por ele, da maneira que ele acreditava ser mais simples e mais explicativa para seu aprendizado, e todas as ferramentas estavam à sua disposição para utilizar no seu processo de aprendizagem.

As considerações feitas acerca da aprendizagem, apresentadas nos gráficos, estão relacionadas com os conteúdos indicados através de números, para cada aluno, como indicado na tabela 2 e as classificações expressas na tabela 1; ou seja, cada número relacionado a um nível de aprendizagem é um conteúdo trabalhado. É possível perceber, através dos gráficos 1 e 2, que o método de aluno descobridor é muito mais assertivo no processo de aprendizagem de alunos com deficiência intelectual e/ou cognitiva do que o método de aluno ouvinte. É possível perceber também que em alguns casos, como para o aluno $A 3$, em alguns conteúdos não se detectou qualquer aprendizagem, independentemente do método. Acredita-se que isto acontece pela falta de interesse sobre o conteúdo trabalhado, ou até pela falta de ferramenta mais adequada que pudesse auxiliar melhor o processo.

É possível perceber, através dos gráficos, que o método de aluno descobridor possui, para dois alunos, maior eficácia, na maioria dos conteúdos, enquanto o método de aluno ouvinte não permitiu aprendizagem plena para qualquer dos alunos, em nenhum dos conteúdos trabalhados, exceto no conteúdo 4 para o aluno A1.

Os resultados obtidos neste estudo e que estão resumidos nestes gráficos, mostram claramente estar em sintonia com as ideias seguidas pelas áreas da pedagogia (MANTOAN, 2015), (FREIRE, 1994) e também da psicologia (SAMPAIO, 2009), (FERNANDÉZ, 2001), de que a educação tradicional não deve constituir um meio contínuo de aprendizagem, nem para alunos sem deficiência e com ainda menos probabilidade de aprendizagem para estudantes com algum tipo de deficiência.

Gráfico 1- Método aluno ouvinte - com diversas ferramentas 


\section{Educação Especial}

\section{http://dx.doi.org/10.5902/1984686X27590}

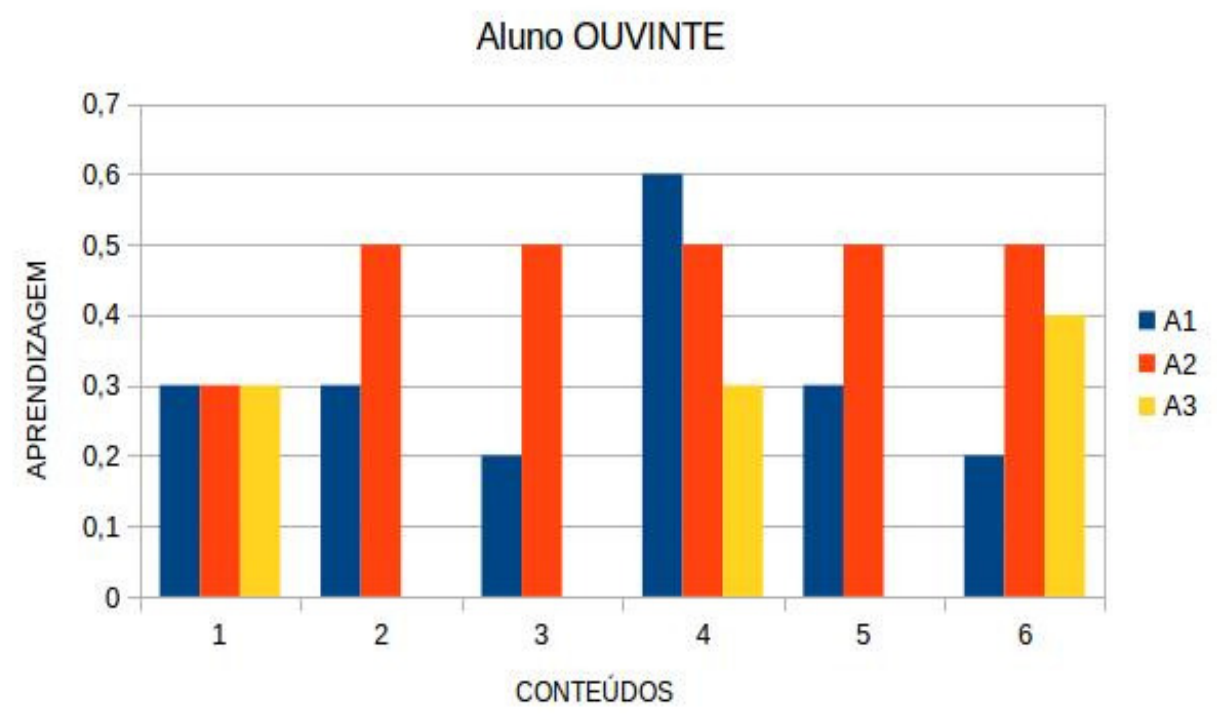

Gráfico 2 - Método aluno descobridor - com diversas ferramentas

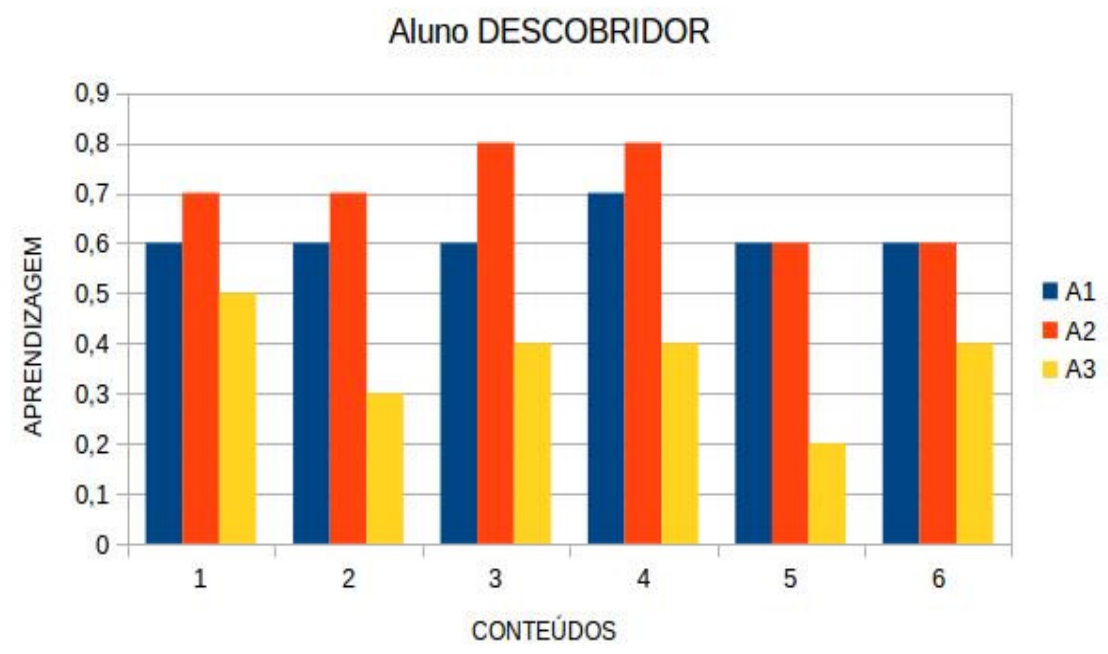

\section{Conclusão}

A educação inclusiva é uma realidade, regida por lei, tanto no Brasil quanto em Portugal, mas ainda são poucas as intervenções que ocorrem para que os alunos com deficiência sejam efetivamente incluídos no processo de ensino e aprendizagem e tenham as mesmas possibilidades de sucesso dos demais estudantes.

Esta pesquisa mostra que apesar dos perfis apresentados, todo estudante é capaz de aprender desde que o professor e a escola saibam organizar o processo de ensino e aprendizagem, que permitam a variação de metodologias e os trabalhos em 
http://dx.doi.org/10.5902/1984686X27590

grupo. O ensino de Física requer formação continuada visto que, por exemplo, as tecnologias permitem uma maior inclusão no meio escolar e também auxiliam nas aplicações de conceitos básicos que muitas vezes não são compreendidos. Além disso, não se faz educação inclusiva sem professores conhecedores da sua área de formação. Contudo, uma formação pedagógica e também uma formação específica, continuada, são imprescindíveis para o sucesso do processo de ensino e aprendizagem.

Fazer a educação inclusiva acontecer em sala de aula é perceber que cada estudante, com ou sem deficiência, aprende de maneira diferente, e como tal precisa de ferramentas e métodos diferenciados. Os alunos com deficiências mais pronunciadas no aspecto cognitivo e também os com deficiências diversas, precisam de mais tempo, de um currículo que permita seu aprendizado de forma inclusiva e não igualitária, mas também não apenas integrada.

É preciso que as aulas de forma geral, mas especificamente de Física, sejam ricas em experimentos, jogos didáticos, recursos tecnológicos e que, principalmente, o aluno seja participante de seu aprendizado, não apenas ouça explicações, mas participe efetivamente no contexto do processo de ensino.

Apesar desta pesquisa ter sido realizada individualmente, espera-se utilizar os dados, os métodos e as ferramentas didáticas em salas de aula regulares, com estudantes com diferentes características, e também no processo inclusivo de forma a poder auxiliar com mais subsídios e pesquisas na área de inclusão nas ciências Físicas.

Do processo desenvolvido, percebeu-se ainda a importância e a necessidade de um maior conhecimento metodológico, tecnológico e científico, por parte tanto de professores da educação especial quanto dos professores das áreas específicas. Uma melhor preparação destes professores é fundamental, para que juntos, possam realmente auxiliar os estudantes em seus desenvolvimentos cognitivos. Apenas o trabalho conjunto da escola, dos profissionais da educação e também da família é que poderá, efetivamente, produzir uma educação de qualidade para a inclusão. 
Referências

http://dx.doi.org/10.5902/1984686X27590

ANDERSON, L.W., et al. A taxonomy for learning, teaching and assessing: a revision of Bloom's taxonomy of educational objectives. Nova York: Addison Wesley Longman. 2001.

BLOOM, B.S.; HASTINGS, J.T.; MADANS, G.F.. Handbook on Formative and Sommative Evaluation of Student Learning. New York: McGraw Hill. 1971.

CAMARGO, E.P; VIVEIROS, E.R.; NARDI. R.. Trabalhando conceitos de óptica e eletromagnetismo com alunos com deficiência visual e videntes. $X$ Encontro de Ensino de Física. Londrina. PR. Anais. 2006.

CARVALHO, E.N.S.; MACIEL, D.M.M.A.. Nova concepção de deficiência mental segundo a American Association on Mental Retardation - AAMR:sistema 2002. Temas em psicologia. v.11, n.2, 2003.

GONÇALVES, C.E.S; VAGULA, E.. Modificabilidade cognitiva estrutural de Reuven Feuerstein: uma perspectiva educacional voltada para 0 desenvolvimento cognitivo autônomo. IX ANPED Sul. Seminário em Pesquisa em Educação da Região Sul. Caxias do Sul. RS. Anais. 2012.

FERNANDÉZ, A.. Os idiomas do aprendente. Porto Alegre. Artmed. 2001.

FEUERSTEIN, R. Instrumental Enrichment - An Intervention Program for Cognitive Modificability, Glenview, Illinois: Scott, Foresman and Company, 1980.

FREIRE, P.. Pedagogia do Oprimido. São Paulo. Editora Paz e Terra. 23 impressão. 1994.

LUCKASSON, R.; BORTHWICK-DUFFY, S.; BUNTINX, W. H. H.; COULTER, D. L.; Craig, E. M.; REEVE, A.; Snell, M. E. et al.. Mental Retardation - definition, classification, and systems of support. Washington, DC: American Association on Mental Retardation. 2002

MANTOAN, M.T. E.. Educação escolar de deficientes mentais: Problemas para a pesquisa e o desenvolvimento. Scielo Brasil. CEDES. Unicamp. SP. jan/abril, 46, 1999.

MANTOAN, M.T. E.. Inclusão escolar: O que é? Por quê? Como fazer? São Paulo. Summus Editorial. 2015.

MONTEIRO, I.G.; TEIXEIRA, K.R.M.; PORTO, R.G.. Os níveis cognitivos da Taxonomia de Bloom: Existe necessariamente uma subordinação hierárquica entre eles? XXXVI EnANPAD. Encontro de Pós-Graduação e Pesquisa em Administração. Rio de Janeiro. RJ. Anais. 2012. 
http://dx.doi.org/10.5902/1984686X27590

PORTUGAL, Lei de 27 de agosto de 2009 Estabelece o regime da escolaridade obrigatória e dá outras providências. Diário da República, 1a série, n. 166. Portugal. 2009 .

SAMPAIO, C.T.; SAMPAIO, S. MR.. Educação Inclusiva: o professor mediando para a vida. Salvador. EDUFBA. 2009.

UNESCO, Declaração de Salamanca e Enquadramento da Acção na Área das Necessidades Educativas Especiais. Instituto de Inovação Educacional, Lisboa, 1994.

VYGOTSKY, L.S.. Mind in Society - The development of higher psychological processes. Cambridge. MA: Harvard Univesity Press. 1978.

\section{Correspondência}

Ângela Maria dos Santos - Instituto Federal do Paraná, R. João Negrão, 1285 Rebouças, CEP: 80230-150, Curitiba, Paraná, Brasil.

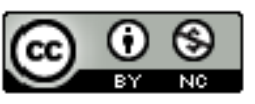

Th is work is licensed under a Creative Commons Attribution-NonCommercial 4.0 International (CC BY-NC 4.0) 